\title{
Water reuse as a secure pathway to deal with water scarcity
}

\author{
Vincenzo Torretta $^{1 *}$, Ioannis Katsoyiannis ${ }^{2}$, Maria Cristina Collivignarelli ${ }^{3}$, Giorgio \\ Bertanza $^{4}$, Maria Xanthopoulou ${ }^{2}$ \\ ${ }^{1}$ Insubria University of Varese, Department of Theoretical and Applied Sciences, via G.B. Vico, 46, I- \\ 21100 Varese, Italy. \\ ${ }^{2}$ Aristotle University of Thessaloniki, Department of Chemistry, Thessaloniki 54124, Greece \\ ${ }^{3}$ University of Pavia, Department of Civil and Architectural Engineering, via Ferrata 1, 27100 Pavia, \\ Italy \\ ${ }^{4}$ University of Brescia, Department of Civil, Environmental, Architectural, Engineering, and \\ Mathematics, via Branze 43, 25123 Brescia, Italy
}

\begin{abstract}
An adequate access to water supply systems is crucial for a sustainable future. Climate change is expected to increase water shortage problems worldwide. Reuse/recycling of treated wastewater for domestic and/or agricultural purposes can be considered an interesting water supply: it is independent from seasonal drought and meteorological variability and able to cover the peak of water demand. In the case of direct reuse, the parameter of treated water must comply with the reuse limits for biological oxygen demand, chemical oxygen demand and suspended solids. In case of indirect reuse, the regulatory approach changes as the dilution ratio between discharge and flow of the irrigation canal is taken into account too. There are many interventions that are considered useful for the purpose of promoting the development of an enhanced water recovery and recycling: legislation improvements, modification in the water storage management, prevention in pollution discharged into sewerage systems, improving the efficiency of WWTPs, incentive the adoption of rainwater storage tanks and interventions for the separation of gray water, establish a "blue certificate" for financing investments. In the present paper those aspects are analysed referring to some cases found in an Italian region.
\end{abstract}

\section{Introduction}

Worldwide, about 844 million people lack basic drinking-water service and 2.3 billion people still do not have basic sanitation facilities, such as toilets or latrines [1]. In 2050, it has been estimated that the world population will reach the $9.4-10.2$ billion people; for that date the demand for water from the industrial sector is expected to increase by $400 \%$ [2]. The increasing demands of fresh and potable water is not only due to population growth, but also to the improvement of living standards, changing in consumption patterns and expansion of irrigated agriculture.

*Corresponding author: vincenzo.torretta@uninsubria.it 
Today, the strongly accentuating problem of water scarcity has become a threat to achieve a sustainable development of human society. This is particularly true for countries with rapid economic growth, or for those where a large part of the population has no access to modern facilities: wastewater treatment plants (WWTP), sewerage systems, potabilization systems, aqueducts, wells, among others $[3,4]$. Access to good quality water in sufficient amounts is a key aspect for the life of all human beings and for most economic activities in many sectors [5-10]. Globally, the amount of fresh water is sufficient to serve the population. However, the spatial and temporal variations in demand and availability are the main issues that increase the issues of water scarcity in different areas of the world $[11,12]$.

Water scarcity is exacerbated or even driven also by climate change and the general increase in temperature: globally, about $98 \%$ of water is salty and only $2 \%$ is sweet. Of this $2 \%$, almost $70 \%$ is represented by snow or ice, $30 \%$ is groundwater, less than $0.5 \%$ is surface water (lakes and rivers) and less than $0.05 \%$ is located in the atmosphere. The main effect of heating consists in melting polar ice, increasing water amount in the atmosphere (causing more intense and abundant rainfalls), transformation of snowfall into rain (causing evaporation).

According to the European Commission (EC), water scarcity is defined as a situation of long-term water imbalance, where the demand for water exceeds the level of available water resources. This situation usually occurs in areas with low water availability or scarce precipitation, and in regions with high water consumption due to high population density, significant volumes of water used for agricultural or industrial activities, and due to water losses among the water pipelines [13].

About half of the European Countries, which represent about $70 \%$ of the entire population, are facing the problem of "water stress", due to the scarcity of water resources and the reduction of its quality. This has led many countries to seek greater efficiency in the use of water resources, including greater awareness of reuse practices [14-16].

The "water stress index=WSI" was introduced for the EU countries and represents the ratio between the amount of water released and the renewable resources of fresh water available: below $10 \%$ - low WSI; values between 10 and $20 \%$ - water availability is decreasing and that significant investments are needed to ensure adequate water supplies, above $20 \%$ - the need for large-scale projects aimed at balancing the water demand and its supply, with interventions aimed at solving conflicts regarding competition uses. Analysing the results reported by the European Environmental Agency (EEA), in the future, the main Mediterrean water basins will be affected by an increase in water stress levels. Italy appears to be in a "moderate" risk situation and in some areas also "severe" [13].

In principle, any type of wastewater (domestic, urban or industrial) can be considered interesting for reuse. Its reuse can provide significant environmental, social and economic benefits [17-19]. Water reuse can improve the state of the environment quantitatively, reducing the resources consumption, and qualitatively, reducing the pollutants that the WWTP transfers to the water bodies. Moreover, compared to alternative water supply facilities, such as desalination or trucks water transfer, the reuse of wastewater typically requires lower investment and operating costs [20]. The reuse of treated wastewater can be considered a reliable water supply, completely independent from seasonal drought and meteorological variability and able to cover the peak of water demand.

In Italy, the aqueducts (425 thousand km network) recorded an average loss percentage of about 39\%, with important geographical differences: in Northern Italy, the losses amounted to $26 \%$, in Central Italy to $46 \%$ and in the South $45 \%$. About $60 \%$ of the national network was installed over 30 years ago and $25 \%$ has exceeded 50 years. The renewal rate is equal to 3.8 meters of pipelines for each km of network: at this rate it will take more than 
250 years to replace the entire network [21]. Among the 116 provincial capitals, there is $35.4 \%$ of average water network losses (year 2015).

The present paper presents data regarding WWTP from North of Italy and indicate some interventions that can be made in order to comply with the reuse of the treated wastewater.

\section{Material and methods}

The research study started by analysing the data from 23 WWTP belonging to the Lambro-Seveso-Olona area in order to check the possibility to use the produced treated water in the agriculture sector. It was noticed that the critical parameters are suspended solids (SS), total nitrogen $\left(\mathrm{TN}_{2}\right)$, total phosphorus (TP), surfactants and E. coli, although several plants were equipped with treatments of filtration and final disinfection.

The qualitative characteristics of the treated waters depend on how these waters reach agricultural use:

- unloading in direct pipelines to agricultural land or irrigation canals, without mixing with water from other sources (direct reuse);

- unloading into canals (exclusively irrigated) where there is a mixing with water from other sources already present in the canals (indirect reuse).

In the case of direct reuse, the adoption of a filter-flocculation system can guarantee compliance with the reuse limits for biological oxygen demand $\left(\mathrm{BOD}_{5}\right)$, chemical oxygen demand (COD) and SS parameters. Disinfection is essential and can guarantee the limit imposed for the E. coli [21]. Other treatments can be added in order to avoid problem with acute toxicity, surfactants and Sodium Adsorption Ratio (SAR) [22-25]

In case of indirect reuse the limits for $\mathrm{COD}, \mathrm{BOD}^{5}, \mathrm{SS}$, nitrogen and phosphorus, $\mathrm{E}$. coli to be respected in Italy, are intermediate between those imposed by the D.M. 185/2003 or Regional Regulation and those of Legislative Decree no. 152/06 for releasing in surface water, according to the dilution ratio between discharge and flow of the irrigation canal $[26,27]$.

\section{Results and Discussions}

Considering the data from Table 1, 62\% of the WWTP analysed are suited for treated wastewater reuse (agricultural and industrial). The preferential scenario of intervention is the indirect reuse of wastewater through irrigation canals: the discharge limits (COD, $\mathrm{BOD}_{5}, \mathrm{SS}, \mathrm{TN} \mathrm{N}_{2}, \mathrm{TP}$ ) essentially coincide with those for discharge into surface waters. The length of the adductor's channels used for the distribution of the treated water was variable from a minimum of $100 \mathrm{~m}$ to a maximum of $3 \mathrm{~km}$, for a total pipeline development of approximately $10.5 \mathrm{~km}$. As regards the hydraulic works, a general sizing of the pipelines was supposed to be introduced and, where necessary, a pumping plant.

The direct reuse of treated wastewater would involve the adoption of very expensive treatments for the removal of specific pollutants (i.e. surfactants), without forgetting that SAR occurred in wastewater, and these pollutants affect the agricultural crops.

In agriculture, wastewater reuse can be implemented for six months each year, while the industrial reuse can be practiced for the entire year. The annual volume of recoverable water was estimated at $380 \mathrm{Mm}^{3}$ per year, corresponding to about $46 \%$ of the total annual volume treated by all the considered WWTP. Moreover, the direct discharge in surface water bodies of a similar percentage of nitrogen and phosphorus would be avoided.

Regarding the economic requirements, for the indirect reuse of wastewater no interventions should be provided. The investment for improving the purification system of a WWTP was estimated at about the same order of magnitude of the conventional 
investment. For irrigation reuse, the sizing of the pipelines for accepting the WWTP releases requires investment costs for about 10.6 million $€$. These investments can be part introduced without significant changes.

Table 1. Plant intervention and hydraulic works for reusing the wastewater after treatment

\begin{tabular}{|c|c|c|c|c|c|c|c|c|c|c|c|}
\hline \multirow[b]{2}{*}{ 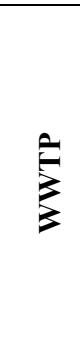 } & \multirow{2}{*}{ 离 } & \multicolumn{3}{|c|}{$\begin{array}{c}\text { Tertiary } \\
\text { treatment } \\
\text { available }\end{array}$} & \multirow{2}{*}{ 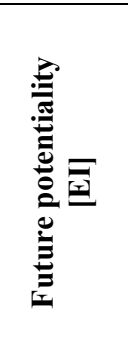 } & \multirow{2}{*}{ 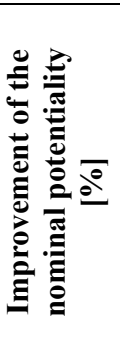 } & \multicolumn{3}{|c|}{$\begin{array}{c}\text { Tertitiary } \\
\text { treatment to be } \\
\text { introduced }\end{array}$} & \multirow[b]{2}{*}{$\underset{\mathscr{0}}{\mathscr{\varrho}}$} & \multirow{2}{*}{ 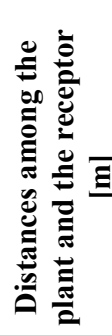 } \\
\hline & & 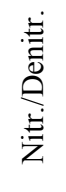 & 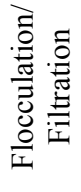 & 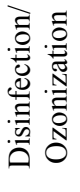 & & & 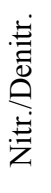 & 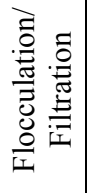 & 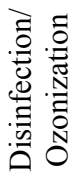 & & \\
\hline 1 & $\begin{array}{c}1,250,00 \\
0\end{array}$ & $\bullet$ & $\bullet$ & $\bullet$ & $\begin{array}{c}1,250,00 \\
0\end{array}$ & 0 & & & & A & \\
\hline 2 & $\begin{array}{c}1,050,00 \\
0\end{array}$ & $\bullet$ & $\bullet$ & $\bullet$ & $\begin{array}{c}1,050,00 \\
0\end{array}$ & 0 & & & & A & \\
\hline 3 & 600,000 & $\bullet$ & $\bullet$ & $\bullet$ & 700,000 & 17 & & & & A & 1900 \\
\hline 4 & 566,000 & $\bullet$ & $\bullet$ & $\bullet$ & 900,000 & 59 & & & & $\mathrm{~A}$ & 30 \\
\hline 5 & 400,000 & $\bullet$ & $\bullet$ & $\bullet$ & 400,000 & 0 & & & & $\mathrm{~A}$ & 1000 \\
\hline 6 & 360,000 & $\bullet$ & $\bullet$ & $\bullet$ & 720,000 & 100 & & & & A & \\
\hline 7 & 300,000 & & & $\bullet$ & 300,000 & 0 & $\bullet$ & $\bullet$ & & A & 3000 \\
\hline 8 & 270,000 & & & $\bullet$ & 270,000 & 0 & $\bullet$ & $\bullet$ & & A & 1800 \\
\hline 9 & 195,000 & $\bullet$ & & $\bullet$ & 187,302 & 0 & & $\bullet$ & & I & \\
\hline 10 & 154,000 & $\bullet$ & $\bullet$ & $\bullet$ & 212,598 & 38 & & & & - & \\
\hline 11 & 140,000 & $\bullet$ & $\bullet$ & $\bullet$ & 186,167 & 33 & & & & - & \\
\hline 12 & 137,544 & $\bullet$ & & $\bullet$ & 220,000 & 60 & & $\bullet$ & & - & \\
\hline 13 & 130,000 & n.a. & n.a. & n.a. & 150,000 & 15 & - & - & - & $\mathrm{A}$ & 200 \\
\hline 14 & 120,000 & $\bullet$ & & $\bullet$ & 260,000 & 117 & & $\bullet$ & & $\mathrm{I}$ & \\
\hline 15 & 120,000 & $\bullet$ & & $\bullet$ & 120,000 & 0 & & $\bullet$ & & - & \\
\hline 16 & 105,000 & & $\bullet$ & $\bullet$ & 140,000 & 33 & $\bullet$ & & & $\mathrm{A}$ & \\
\hline 17 & 100,000 & n.a. & n.a. & n.a. & 100,000 & 0 & - & - & - & $\mathrm{A}$ & \\
\hline 18 & 96,000 & $\bullet$ & $\bullet$ & $\bullet$ & 131,736 & 37 & & & & - & \\
\hline 19 & 80,000 & n.a. & n.a. & n.a. & 120,000 & 50 & - & - & - & $\mathrm{A}$ & 150 \\
\hline 20 & 75,000 & $\bullet$ & & $\bullet$ & 119,507 & 59 & & $\bullet$ & & $\mathrm{A}$ & 2100 \\
\hline 21 & 74,500 & & $\bullet$ & & 135,000 & 81 & $\bullet$ & & $\bullet$ & $\mathrm{A}$ & 100 \\
\hline 22 & 60,000 & $\bullet$ & $\bullet$ & $\bullet$ & 90,000 & 50 & & & & $\mathrm{~A}$ & 150 \\
\hline 23 & 51,000 & & $\bullet$ & $\bullet$ & 75,000 & 47 & $\bullet$ & & & $\mathrm{A}$ & \\
\hline 24 & 34,139 & $\bullet$ & & & 60,000 & 76 & \multirow{2}{*}{\multicolumn{3}{|c|}{$\wedge$}} & - & \\
\hline 25 & 20,000 & n.a. & n.a. & n.a. & 36,228 & 81 & & & & I & \\
\hline 26 & - & - & - & - & 345,830 & - & - & - & - & - & \\
\hline \multicolumn{12}{|c|}{$\begin{array}{l}\text { F For these WWTP, the water reuse is for industrial purposes. So, the plant impr } \\
\text { be specified. } \\
\text { A: Direct reuse for agriculture (in bold the WWTP that just reuse the wastewater) } \\
\text { I: industrial reuse; n.a.: not available } \\
{ }^{\circ} \text { The pumping station should be forecasting }\end{array}$} \\
\hline
\end{tabular}

\section{Conclusions}

The recovery of treated wastewater represents a "green" choice and is now becoming a perspective to counteract the scarcity of water that is pending throughout the world. The 
water recovery (rainwater harvesting) and recycling (wastewater treatment and recovery) allow achieving two important results: saving of drinking water and reduction of rainwater sent to the WWTP, with significant improvements in cost savings and treatment efficiency.

Taking into account the presented research it can be noticed that :

- the direct reuse of wastewater does not appear to be widely applied except in those areas where the cost of the primary resource is very high and therefore the reuse of wastewater is of economic advantage;

- the perspective of indirect reuse is very different: this practice is already widely adopted and can represent an interesting way to recover water resources, improving the quality of water bodies.

There are many interventions that are considered useful for the purpose of promoting the development of water recovery and recycling:

- to make legislation (especially in the field of quality required for irrigation reuse) less rigid, which often makes difficult to use treated water, even of good quality (a draft EU legislation on reuse is currently under discussion).

- maximizing the volumes in lakes (or artificial water basins).

- stringent control and monitoring on the quality of releases into urban sewage systems, to facilitate the treatment for reuse purposes.

- improving the efficiency of WWTPs with a specific methodological approach, as already suggested in recent years for the drinking water treatment plants $[11,29,30]$.

- incentive the adoption of rainwater storage tanks and interventions for the separation of gray water with consequent use for non-potable purposes, also through the use of fiscal instruments.

- establish a "blue certificate" for financing investments in the field of water efficiency in the industrial, agricultural and service sectors.

- building new civil structures with suitable water saving and rainwater redeployment facilities.

A complex decision-making process must then be based on robust and transparent procedures [31,32]. The technical interventions to be implemented must be identified through careful planning at the river basin level. The aspects to consider (environmental, economic, technical-operational, social, administrative) make planning a very complex activity.

Authors would like to thank S. Papiri, C. Collivignarelli, F. Prandini, and R. Corradini for their help in the research activities.

\section{References}

1. Progress on Drinking Water, Sanitation and Hygiene WHO Library Cataloguing-in-Publication Data. Available on https://www.who.int/mediacentre/news/releases/2017/launch-version-reportjmp-water-sanitation-hygiene.pdf

2. The United Nations World Water Development Report 2015: Water for a Sustainable World; facts and figures. Available on https://unesdoc.unesco.org/ark:/48223/pf0000231823.

3. O.O. Ololade, Develop Southern Africa, 35(2), 194-209 (2018).

4. F. Tatti, M. Petrangeli Papini, V. Torretta, G. Mancini, M.R. Boni, P. Viotti, J Contam Hydrol 222, 89-100 (2019)

5. L.M.S. Seelen, G. Flaim, E. Jennings, L.N. De Senerpont Domis, J Environ Manag 242, 246-257 (2019)

6. L.I. Cioca, R. Giurea, I. Precazzini, M. Ragazzi, M.I. Achim, M. Schiavon, E.C. Rada, AIP Conference Proceedings, 1968, 020022, (2018)

7. C. Pradinaud, M. Núñez, P. Roux, G. Junqua, R.K. Rosenbaum, Int J Life Cycle Assess 24(3), 590-603 (2019). 
8. A.C. Flores-Díaz, A.Q. Chacón, R.P. Bistrain, M.I. Ramírez, A. Larrazábal, Water, 10(5), 542 (2018).

9. A.C.C. Soares, R.F. Carmo, p.D. Bevilacqua, P.D., Ciencia e Saude Coletiva, 22(10), 32153223, (2017).

10. E. Trulli, V. Torretta, E.C. Rada, I.A. Istrate, E.A. Papa, INMATEH - Agr Eng 44(3), 121-128 (2014).

11. V. Torretta, Sustainability, 6, 8128-8148 (2014).

12. M. Ragazzi, R. Catellani, E.C. Rada, V. Torretta, X. Salazar-Valenzuela,Sustainability. 8(3), 208 (2016).

13. EEA 2007, Available on https://www.eea.europa.eu/data-and-maps/figures/water-stress-ineurope-2000-and-2030

14. E. Trulli, V. Torretta, E.C. Rada, UPB Sci Bull, serie D, 78(4), 163-174 (2016)

15. F.M. Olowookere, M.O. Alatise, O.T. Faloye, Agr Eng Int: CIGR J, 20(3), $61-70$ (2018)

16. M.S. Baawain, M. Al-JAbri, B.S. Choudri, Iranian J Public Health, 44(11), 1473-1481 (2015)

17. L. Raschid-Sally, D.J. Van Rooijen, Peri-urban Water and Sanitation Services: Policy, Planning and Method, 63-89 (2010)

18. K. Kolecka, H. Obarska-Pempkowiak, M. Gajewska, Rocznik Ochrona Srodowiska, 20, 1350$1371(2018)$

19. R.G. Luthy, D.L. Sedlak, Plumlee M.H., D. Austin, V.H. Resh, Frontiers Ecol Environ, 13(9), 477-485 (2015)

20. A. Gorgoglione V. Torretta, Sustainability, 10(11), 3910, 1-19 (2018).

21. Adnkronos 2017, Available on http://www.adnkronos.com/sostenibilita/risorse/

22. M.C. Collivignarelli, A. Abbà, I. Benigna, S. Sorlini, V. Torretta, Sustainability, 10(1), 86 (2018).

23. M.C. Collivignarelli, A. Abbà, G. Alloisio, E. Gozio, I. Benigna, Sustainability, 9(10), 1704 (2017).

24. M.C. Collivignarelli, R. Pedrazzani, S. Sorlini, A. Abbà, G. Bertanza, Sustainability, 9(2), 244 (2017).

25. M. Papa, R. Pedrazzani, G. Bertanza, Water Res 47(11), 3679-3687 (2013).

26. M Papa, C. Alfonsín, M.T. Moreira, G. Bertanza, J Clean Prod 113, 311-317 (2016).

27. M.C. Collivignarelli, A. Abbà, G. Bertanza, Environ Technol 36(16), 2115-2124 (2015).

28. M. Raboni, R. Gavasci, V. Torretta, Water, Air, Soil Pollut 227(12), 1-12 (2016).

29. S. Sorlini, M.C. Collivignarelli, F. Castagnola, B.M. Crotti, M. Raboni, Water Sci Technol 71(4), 597-604 (2015).

30. M. Langone, R. Ferrentino, G. Trombino, D. Waubert de Puiseau, G. Andreottola, E.C. Rada, M. Ragazzi, UPB Sci Bull, Series D, 77(1), 225-234 (2015).

31. G. Bertanza, P. Baroni, M. Canato, Resour Conserv Recycl 110, 1-5 (2016).

32. G. Bertanza, M. Canato, G. Laera, J Clean Prod 170, 1206-1218 (2018). 